\title{
Gene 10017 encodes a second chaperone for EspA of enterohaemorrhagic Escherichia coli $\mathrm{O} 157: \mathrm{H7}$

\author{
Marcia Shu-Wei Su, Hsi-Chun Kao, Ching-Nan Lin and Wan-Jr Syu
} \\ Correspondence \\ Wan-Jr Syu \\ wjsyu@ym.edu.tw \\ Received 10 October 2007 \\ Revised 6 January 2008 \\ Accepted 8 January 2008

\author{
Institute of Microbiology and Immunology, National Yang-Ming University, Beitou 112, Taipei, \\ Taiwan
}

\begin{abstract}
Escherichia coli O157:H7 tightly associates with host cells through the formation of a pedestal structure in which cell cytoskeleton rearrangement has been observed. These pathogenic located on the bacterial chromosome. Gene 10017 is one of the LEE genes that has been less well characterized. To understand further the function of the gene, an 10017-deleted mutant was created. The mutant lost type III protein secretion (TTS) capacity. In terms of intracellular components, there was a substantial decrease in the level of EspA, but no apparent effect on Tir and EspB was observed. Fractionation of the bacterial proteins indicated that L0017 was part of the inner-membrane fraction. This association with the membrane is consistent with the hypothesis that L0017 may act as one of the TTS components. In addition, L0017 was found to affect regulation of EspA at a post-transcriptional level. The presence of L0017 readily stabilized EspA and the interaction between L0017 and EspA was demonstrated by their co-purification as well as by a bacterial two-hybrid system. Therefore, L0017 is a chaperone, the second chaperone identified in this system after CesAB, and escorts EspA, a protein with a great tendency to polymerize.
\end{abstract} properties have been attributed to an island, known as the locus of enterocyte effacement (LEE),
}

\section{INTRODUCTION}

Enterohaemorrhagic Escherichia coli (EHEC) O157:H7 is an aetiological pathogen that causes diseases that range from bloody diarrhoea to haemolytic uraemic syndrome to acute renal failure (Nataro \& Kaper, 1998). One of the pathogenic mechanisms used by the bacterium is to cause attaching and effacing (A/E) lesions on the intestine, a histopathological change that results from bacteria attaching to enterocytes, destroying the host microvilli and causing the formation of a pedestal-like structure (Frankel et al., 1998). The major virulence factors involved in $\mathrm{A} / \mathrm{E}$ lesions reside on a locus of enterocyte effacement (LEE), a pathogenicity island on the chromosome that has also been found in human enteropathogenic E. coli (EPEC), rabbit EPEC and a mouse pathogen called Citrobacter rodentium. Among these LEEs, there are many genes in common (McDaniel et al., 1995) and the sequences of the various LEEs show a high degree of homology and gene similarity (Deng et al., 2001).

The LEE in EHEC consists of 41 ORFs; these encode the type III secretion (TTS) apparatus (Esc and Sep proteins) (Pallen et al., 2005), effectors (EspF, EspG, EspH, EspI,

Abbreviations: A/E lesion, attaching and effacement lesion; EHEC, enterohaemorrhagic E. coli; EPEC, enteropathogenic E. coli; LEE, locus of enterocyte effacement; TTS, type III secretion.
MAP and Tir) (Crane et al., 2001; Elliott et al., 2001, 2002; Lai et al., 1997; Mundy et al., 2004), translocators (EspA, EspB and EspD) (Chiu et al., 2003; Kenny et al., 1996; Kresse et al., 1999), chaperones (e.g. CesAB, CesD, CesD2, CesF and CesT) (Creasey et al., 2003a, c; Wainwright \& Kaper, 1998), regulators (Ler, GrlR, GrlA and Mpc) (Deng et al., 2004; Mellies et al., 1999; Tsai et al., 2006) and adhesin (intimin) (Donnenberg et al., 1993; Jerse \& Kaper, 1991; Kenny et al., 1997b). While some of them have been thoroughly studied, others remain less well characterized, and gene 10017 of EHEC is one of the latter.

The TTS system secretes translocators and effectors across the inner and outer membranes of the bacteria after appropriate induction. To achieve this function, the system consists of a basal apparatus with proteins distributed over the inner membrane, periplasm and outer membrane (Roe et al., 2003). While the effectors and the translocators are all secreted by the TTS system, subtle differences have been found in their secretion. Overall, 19 LEE genes, when individually deleted, affect secretion of both translocators and effectors, while four others preferentially affect the secretion of translocators (Deng et al., 2004). The counterpart of 10017 in C. rodentium, orf29, is among the 19 genes required for all TTS. This ORF encodes a protein of 92 aa of which $86 \%$ are identical between C. rodentium and EHEC (Deng et al., 2001). In a yeast two-hybrid 
screening, the product of orf 29 has a positive interaction with that of orf2 (10053 in EHEC). Furthermore, orf2 is homologous to Pseudomonas aeruginosa pscE and Yersinia pestis $y s c E$, and the latter binds to YscG (Pallen et al., 2005). By correlation, orf29 is speculated to play the YscG-like role. YscG shares $47 \%$ sequence identity with PscG and has a chaperone-like activity (Day et al., 2000; Quinaud et al., 2005). However, no homology has been found between YscG and the orf 29 product (Pallen et al., 2005). In this study, we have experimentally confirmed the effect of 10017 by deletion and determined the location and biochemical properties of L0017. Intriguingly, L0017 was found to have a chaperone-like function that interacts with and stabilizes EspA.

\section{METHODS}

Bacterial growth and molecular biology manipulations. EHEC (ATCC strain 43888) lacking Shiga toxin genes was used as a parental wild-type (WT) strain for creating deletion mutants. Bacteria were regularly cultured in Luria-Bertani (LB) broth. To activate the TTS of EHEC, minimal M9 medium or Dulbecco's Modified Eagle Medium (DMEM) at $37{ }^{\circ} \mathrm{C}$ with $5 \% \mathrm{CO}_{2}$ was used. Selection media were supplemented with ampicillin $\left(100 \mu \mathrm{g} \mathrm{ml}^{-1}\right)$ or chloramphenicol $\left(34 \mu \mathrm{g} \mathrm{ml}^{-1}\right)$ when required. Oligonucleotides were purchased from either Prisma Biotech or MDBio. Restriction enzymes (New England Biolabs), T4 DNA ligase (TaKaRa) and Taq DNA polymerase (Protech) were used during cloning. DNA sequencing was routinely carried out after PCR cloning and this was done by a contract service (Mission Biotech).

Generation and verification of the deletion mutants. To delete 10017 from the EHEC chromosome, a previously used method of homologous recombination without inserting a selectable marker was employed (Link et al., 1997; Tsai et al., 2006). First, a 5' fragment flanking 10017 was amplified from the chromosomal DNA of the parental WT strain (WT) using primers L17-33909F (5'-GCTGAAGATCTTGCAGAC-3') and L17-34978R(XbaI) (5' -TGCTCTAGACCGCCCACACCAGTATCTTATT- $\left.3^{\prime}\right)$. The PCR product was ligated into the pGEM-T Easy vector (Promega) to create pGEMT1/2-L17. A plasmid, pGEMT-3/4-L17, containing an 10017-3' flanking fragment, was similarly generated using primers $\mathrm{L} 17-35188 \mathrm{~F}(\mathrm{Xba \textrm {I }})$ (5'-TGCTCTAGAGGTAGTGGCTGGGTACGAGGATTT-3') and L17-36194R(SalI) (5'-GTCGACGACTTTTAAGCTCTGTGCGC-3'). From the above plasmids, the two 10017-flanking fragments were cut and ligated to take advantage of the engineered $\mathrm{XbaI}$ and Sall sites within the PCR primers; by so doing, pGEMT-A/B-L17 was obtained. This plasmid was subsequently digested with NotI and SalI and the fragment encompassing the two 10017-flanking segments was gelpurified and ligated with NotI/SalI-restricted pKO3 (Link et al., 1997), to generate pKO3-d17. Thereafter, pKO3-d17 was transformed into the EHEC WT strain to create an 10017-deleted mutant strain, which was named $\Delta \mathrm{L} 17$. To confirm the construction of the 10017deleted strain, PCR was performed using two primer pairs (Fig. 1). Amplification using the primers L19-34637F(XbaI) (5'-TGCTCTAGACGGAATTTGGTTCGT-3') and L19-35660R(SalI) (5'-GTCGACGCGGGCTTAAAACCTAAAGC-3') should give a fragment of $1035 \mathrm{bp}$ from the WT and of $800 \mathrm{bp}$ from $\Delta \mathrm{L} 17$. A second primer pair L17 F (5'-ATGGTTAATGATATTTCTGC-3') and C1R (5'CCACTCGAGTTAAAATCCTCGTACCCAGCC- $3^{\prime}$ ) was also used that should amplify a DNA fragment of $280 \mathrm{bp}$ from the WT and a $50 \mathrm{bp}$ fragment from $\Delta \mathrm{L} 17$. In both cases the putative deletion strain $\Delta \mathrm{L} 17$ produced the latter fragment sizes, confirming deletion of $l 0017$.

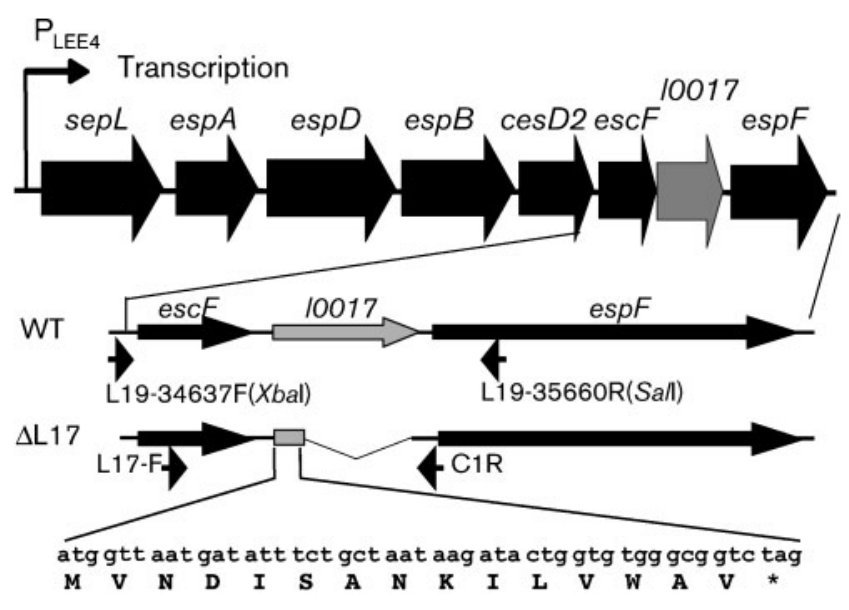

Fig. 1. Schematic representations of the LEE4 operon in the parental (WT) EHEC strain and in the 10017-deleted mutant $(\Delta \mathrm{L} 17)$. Homologous recombination was used to generate $\Delta \mathrm{L} 17$; the remaining nucleotide sequence of 10017 with amino acids encoded is shown. Primers used for PCR amplification and deletion confirmation are also shown with the relative positions marked.

Generation of the 10036 deletion mutant $(\Delta \mathrm{L} 36)$ has been described previously (Tsai et al., 2006).

Plasmid construction. The entire 10017 DNA fragment was amplified by PCR using primers pUC(-)FB (5'-ACTAGTGGATCCAGAATT-3') and pUC(-)RK (5'-ATGGTACCGCCGCCACTCAT-3') from pUC-T-L17, which contains the full-length 10017. The PCR product was cut with BamHI/KpnI and ligated into pQE-30 (Qiagen), which had been digested with the same enzymes, to create pQH-L17. This construct was designed to express full-length L0017 protein with a RGS-His $\times 6$-tag attached to the $\mathrm{N}$ terminus. The DNA in the construct was verified by sequencing. To clone espA into pQE-60 (Qiagen), primers ESPA-1 (5'-CTAACCATGGATACATCAAATGCA- $\left.3^{\prime}\right)$ and ESPA-3R (5'-CGCAGATCTTTTACCAAGGGATATTGC- $3^{\prime}$ ) were used to amplify espA from EHEC genomic DNA. The PCR product was then digested with $\mathrm{NcoI}$ and BglII, and cloned into NcoI/BglII-restricted pQE-60 to give pQ-EspA. Plasmid $\mathrm{pB}_{312}$, expressing $e s p B$, was also derived from $\mathrm{pQE}-60$ and has been described previously (Chiu et al., 2003); it was renamed pQ-EspB for this paper.

Transcriptional fusion and translation fusion reporter constructs. The EspA-LacZ translational fusion construct pKMespAL and the transcriptional fusion construct pKMespAX were generated using pKM005 that contains a promoterless lac $Z$ reporter gene (Masui et al., 1983; Lee \& Cerami, 1987). The espA fragment was PCR-amplified from pQ-EspA using the primers XT5 (5'GCTCTAGACCCGAAAAGTGCCACCTG- $\left.3^{\prime}\right)$ and ESPARB (5'TTGGATCCTTACCAAGGGATATTGC-3'). The PCR product was restricted with $\mathrm{XbaI} / \mathrm{BamHI}$ and ligated into pKM005 that had been digested with the same enzymes; the result was pKMespAL. Similarly, espA was PCR-amplified using the primers XT5 and ESPARX (5'GCTCTAGATTATTTACCAAGGGATATTGC- $3^{\prime}$ ), and the product was treated with $X b a \mathrm{I}$ and then ligated into $\mathrm{XbaI}$-treated, calf intestinal phosphatase-digested pKM005 to generate pKMespAX.

pEspA-His-L0017 was constructed by amplification of espA from pQEspA using primers XhoI-EspA-F (5'-CCGCTCGAGAAATCATAAAAAAT- $3^{\prime}$ ) and XhoI-EspA-R (5'-CCGCTCGAGTTTACCAAGGG$\left.3^{\prime}\right)$. The PCR product was inserted into XhoI-treated pQE-30 after 
digestion with XhoI. The resulting plasmid, pT5-EspA, was next restricted with BamHI and $K p n \mathrm{I}$, and ligated with a BamHI-KpnI fragment obtained from $\mathrm{pQH}-\mathrm{L} 17$ that encodes RGS-His $\times 6$-tagged L0017. The plasmid thus obtained simultaneously encodes tag-free EspA and RGS-His $\times 6$-tagged L0017. By making the above construction, expression of each gene in either transcriptional fusion or translational fusion is driven by an exogenous $\mathrm{T} 5$ promoter.

Measurement of $\boldsymbol{\beta}$-galactosidase activity. The method (Miller, 1972) used ONPG as the substrate. Basically, bacterial transformants were cultivated at $30{ }^{\circ} \mathrm{C}$, and three representative colonies were picked and measured in triplicate for enzyme activity. Each value was individually calibrated with respect to bacterial growth density (Miller, 1972).

Adherence activity of bacteria to HeLa cells. A previously described method (Chiu \& Syu, 2005) was followed with a slight modification. HeLa cells were seeded in 6 -well plates $\left(2 \times 10^{5}\right.$ cells per well) in DMEM supplemented with $10 \%$ fetal calf serum (FCS) and ampicillin $\left(100 \mu \mathrm{g} \mathrm{ml}^{-1}\right)$ for $40 \mathrm{~h}$. Prior to infection, the wells were washed with DMEM without FCS. The monolayer of cells was infected with the various EHEC strains, which had been grown overnight and then diluted $1: 100$. The infections were then allowed to proceed for $6 \mathrm{~h}$. After discarding the supernatants, the wells were washed with phosphate-buffered saline (PBS) five times at $4{ }^{\circ} \mathrm{C}$. Then the HeLa cells were scraped into new microcentrifuge tubes and pelleted down by centrifugation at $1800 \mathrm{~g}$ for $5 \mathrm{~min}$ at $4{ }^{\circ} \mathrm{C}$. Finally, the HeLa cells were lysed and the total number of bacteria associated with the cells in a well was counted on LB-ampicillin agar plates.

Actin fluorescence staining of HeLa cells. Immunofluorescence microscopy analysis was carried out as described by Kresse et al. (1999).

Immunoblotting. EHEC-secreted proteins and bacterial total protein lysates were prepared and analysed as described previously (Chiu \& Syu, 2005; Kenny et al., 1997a). Anti-L0017 was prepared by immunizing mice with purified recombinant proteins from $E$. coli JM109. Anti-EspA, anti-EspB and anti-Tir have been described previously (Tsai et al., 2006). Immunoblots were developed with Renaissance Western Blot Chemiluminescence Reagent Plus (NEN) and the images were captured using X-ray film (Fuji).

Bacterial cell fractionation. To separate bacterial proteins into fractions, the method of Neves et al. (2003) was slightly modified. EHEC was inoculated into M9 medium $(200 \mathrm{ml})$ and grown for $6 \mathrm{~h}$ at $37{ }^{\circ} \mathrm{C}$ in the presence of $5 \% \mathrm{CO}_{2}$. The bacteria were then pelleted by centrifugation at $4{ }^{\circ} \mathrm{C}$. After removing the supernatants, the pellets were weighed and resuspended by adding $50 \mathrm{ml}$ osmotic shock buffer A $(20 \%$ sucrose, $20 \mathrm{mM}$ Tris, $\mathrm{pH} 8.0) \mathrm{g}^{-1}$. EDTA, at a final concentration of $1 \mathrm{mM}$, was subsequently added and this was followed by gentle shaking at $4{ }^{\circ} \mathrm{C}$ for $10 \mathrm{~min}$. The cells were then centrifuged at $8000 \mathrm{~g}$ for $20 \mathrm{~min}$ at $4{ }^{\circ} \mathrm{C}$ and then the supernatants were removed. The pellets were resuspended by adding $50 \mathrm{ml}$ osmotic shock buffer $\mathrm{B}(5 \mathrm{mM} \mathrm{MgSO} 4) \mathrm{g}^{-1}$, which was followed by gentle shaking at $4{ }^{\circ} \mathrm{C}$ for $10 \mathrm{~min}$. The supernatants were collected by centrifugation as described above. The resulting supernatants were combined for individual cultures and the periplasmic proteins thus obtained were concentrated using a Centricon (Millipore). The bacterial pellets were resuspended in $16 \mathrm{ml}$ lysis buffer (100 mM Tris/ $\mathrm{HCl}, \mathrm{pH} 7.5,1.0 \mathrm{mM}$ PMSF, $0.5 \mu \mathrm{l}$ aprotinin $\mathrm{ml}^{-1}$ ) and the bacteria were disrupted by five passages through a French pressure press. After centrifugation at $14000 \mathrm{~g}$ for $20 \mathrm{~min}$ at $4{ }^{\circ} \mathrm{C}$, the collected supernatants were spun in an ultracentrifuge at $80000 \mathrm{~g}$ for $30 \mathrm{~min}$ at $4{ }^{\circ} \mathrm{C}$. The resulting supernatants were then concentrated using a Centricon and saved as the cytosolic fraction. The pellets with the membrane fractions were further processed into outer- and inner-membrane fractions by washing once with lysis buffer and resuspension in $1.6 \mathrm{ml}$ sarkosyl buffer $(10 \mathrm{mM}$ Tris/ $\mathrm{HCl}, \mathrm{pH} 8$, containing $100 \mathrm{mM} \mathrm{NaCl}, 1.0 \mathrm{mM}$ PMSF, $0.5 \mu \mathrm{l}$ aprotinin $\mathrm{ml}^{-1}$ and $0.5 \% \mathrm{~N}$-lauroylsarcosine). The suspensions were incubated at $4{ }^{\circ} \mathrm{C}$ for $4 \mathrm{~h}$ to obtain suitable dissolution of the inner-membrane proteins. After another ultracentrifugation step, the supernatants containing the inner-membrane proteins were obtained and subsequently concentrated using a Centricon. Finally, the remaining pellets were dissolved in SDS sample buffer and these samples were defined as the outer-membrane fraction. To inspect how well the fractionation was performed, proteins known to be enriched within each compartment were examined by Western blotting. CesD2 has been reported as a chaperone for EspD (Neves et al., 2003) and this protein is found in both the inner-membrane and the cytosolic fraction; the protein was detected with mouse anti-CesD2 polyclonal antibodies (M. S.-W. Su $\&$ W.-J. Syu, unpublished data). The outer-membrane protein OmpC was detected by a mouse polyclonal anti-OmpC. The periplasmic maltose-binding protein (MBP) was detected using a mouse $\mathrm{mAb}$ (SC1D7) (Hsu et al., 1997).

Co-purification of EspA and L0017. Affinity binding of a His $\times 6$ tagged protein to a $\mathrm{Ni}^{2+}$-NTA agarose column (Qiagen) was carried out as described previously (Chiu \& Syu, 2005) except for the buffers. In this case, the buffer used for equilibration and lysis was $50 \mathrm{mM}$ $\mathrm{NaH}_{2} \mathrm{PO}_{4}$, pH 8.0, containing $300 \mathrm{mM} \mathrm{NaCl}, 10 \mathrm{mM}$ imidazole and $1 \mathrm{mM}$ PMSF, and the washing buffer consisted of $50 \mathrm{mM} \mathrm{NaH}_{2} \mathrm{PO}_{4}$, $\mathrm{pH} 8.0,300 \mathrm{mM} \mathrm{NaCl}$ and $50 \mathrm{mM}$ imidazole. Finally, the elution buffer was identical to that used for washing except that imidazole was added at $250 \mathrm{mM}$.

Bacterial two-hybrid assay. The system (Stratagene) was used as described previously (Tsai et al., 2006). In essence, pBT, which encodes the $\lambda$ cI protein, was used to produce a bait protein fused with $\lambda \mathrm{cI}$, and pTRG was used to generate a target protein fused to the $\mathrm{C}$ terminus of an N-terminal domain of the RNA polymerase $\alpha$ subunit. Interactions of the bait and target proteins in the system would then yield a high level of $\beta$-galactosidase expression, the activity of which was measured as described above.

\section{RESULTS}

\section{Effect of 10017 deletion on cell adhesion and actin rearrangement}

To address the role of 10017 in the EHEC TTS, the entire gene, except for the region encoding the first $15 \mathrm{~N}$-terminal residues was deleted by homologous recombination (Fig. 1). The resultant mutant strain $(\Delta \mathrm{L} 17)$ was confirmed by PCR using two sets of primer pairs that gave amplified PCR fragments of the expected sizes. Direct sequencing of an 800 bp PCR fragment, amplified using primers L19$34637 \mathrm{~F}(\mathrm{XbaI})$ and L19-35660R(SalI), indicated a precise excision at the intended junction (Fig. 1). This mutant was then tested for adherence activity with HeLa cells. $\Delta \mathrm{L} 17$ appeared to have lost most of its adherence activity, retaining only $4 \%$ residual adherence when compared to the parental strain transformed with the control vector pQE-30. After complementation with L0017 expression from $\mathrm{pQH}-\mathrm{L} 17$, this mutant's adherence activity was restored to $94 \%$ of the control. When $\Delta \mathrm{L} 17$ was used to infect HeLa cells that were subsequently examined by immunofluorescence staining, no cytoskeleton 
rearrangement and actin aggregation were observed (data not shown).

\section{Localization of L0017 in the inner-membrane fraction}

To elucidate the potential function of 10017 , it is of value to establish the location to which L0017 moves after ribosomal synthesis. To do so, WT bacteria were activated to express LEE proteins in M9 medium, and total bacterial lysate was fractionated. No fraction gave a positive L0017 signal when analysed by Western blotting using a specific antibody raised against recombinant L0017. We reasoned that the intrinsically expressed L0017 might be at such a low level that it was beyond the sensitivity of the Western blot (Fig. 2a). To circumvent this difficulty, plasmid pQHL17 was transformed into the EHEC WT strain and protein fractionation was carried out again. Proteins from the individual fractions were likewise analysed by Western blotting, except that an additional antibody, anti-His $\times 6$ tag, was used (compare Fig. 2a and b). Fig. 2(b) shows that L0017 was concentrated in the inner-membrane fraction (lane IM). The identification of L0017 in the innermembrane fraction is supported by positive detection using both anti-L0017 and anti-His $\times 6$. The fractionation was

(a)

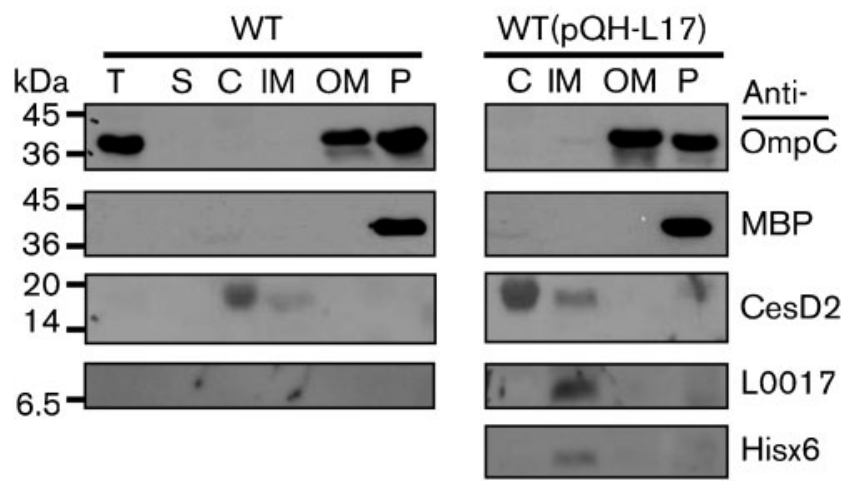

Fig. 2. Biochemical localization of L0017. EHEC was transformed with or without plasmid pQH-L17 (expressing 10017) and the bacteria were cultured to activate the LEE island. The cultures were separated into total bacteria $(T)$ and spent media $(S)$, the latter being subsequently concentrated. After disruption in a French pressure press, the bacteria were fractionated into cytoplasm (C), inner-membrane (IM), outer-membrane (OM) and periplasm $(P)$ fractions. Samples were analysed by Western blotting with antibodies against representative proteins enriched in individual fractions: OmpC (40 kDa), outer-membrane porin C; MBP $(43 \mathrm{kDa})$, periplasmic maltose-binding protein; CesD2 (16 kDa), inner-membrane chaperone for EspD (Neves et al., 2003). Anti-L0017 is a polyclonal antibody raised in mice against RGS-His $\times 6$-tagged L0017, whereas commercial anti-His $\times 6 \mathrm{mAb}$ reacts only with the His $\times 6$ tag. itself successful as shown by the correct detection of the fraction marker proteins OmpC, MBP and CesD2.

\section{Effect of deleting 10017 on representative TTS proteins}

The presence of L0017 in the inner membrane supports the notion that L0017 is a component of the TTS apparatus (Deng et al., 2004). To further explore the effect of deleting this gene, the synthesis and secretion of representative LEE proteins were examined. Like the C. rodentium $\Delta$ orf 29 strain (Deng et al., 2004), no Tir, EspA and EspB were detected in the spent media produced by $\Delta \mathrm{L} 17$ (Fig. $3 \mathrm{~b}$, lane 2), unless $\Delta \mathrm{L} 17$ was further transformed with $\mathrm{pQH}-$ L17 (Fig. 3b, lane 3). It is worth noting that overexpressed L0017 was not found in the concentrated media and was only found in the bacterial lysate (Fig. 3a). In the bacterial lysate, it was also notable that the deletion of 10017 affected the intracellular level of EspA, but not that of Tir or EspB (Fig. 3a, lane 2). Again, the decrease in the level of EspA in $\Delta \mathrm{L} 17$ could be restored by complementation by $\mathrm{L} 0017$ expression ectopically (Fig. 3a, lane 3 ).

\section{Effect of deleting 10017 on ectopically expressed EspA}

To exclude the possibility that the transcription of LEE4 was modulated by L0017, the expression levels of EspA and EspB driven by the same exogenous T5 promoter based upon pQE-60 were examined (Fig. 4a, lanes 3-6). While comparable levels of EspB were detected in the WT and $\Delta \mathrm{L} 17$ strains (lanes 5 and 6), the levels of EspA in the two strains differed greatly (lanes 3 and 4). Therefore, the absence of L0017 indisputably affects the intracellular level of EspA, regardless of their associated promoters. To carry out controls, we examined expression in two additional mutants of EHEC. In C. rodentium, it has been observed that deletion of orf16 (equivalent to EHEC 10032) affects the secretion of translocators, but favours that of effectors. Therefore, we created an 10032 deletion mutant $(\Delta \mathrm{L} 32)(\mathrm{J}$. C.-W. Lio \& W.-J. Syu, unpublished results), and repeated the transformation and analyses for EspA and EspB as described above. The results of Fig. 4(b) show that there is no apparent difference in the intracellular levels of these proteins between the WT and $\Delta \mathrm{L} 32$ strains (EspA, lanes 1 and 2; EspB, lanes 3 and 4). The observed protein levels in the second mutant, $\Delta \mathrm{L} 36$ (Fig. $4 \mathrm{c}$ ), were similar to those observed in the WT and $\Delta \mathrm{L} 32$ strains. Therefore, the low expression level of EspA in $\Delta \mathrm{L} 17$ is a unique property. It is worth noting that $\Delta \mathrm{L} 36(\Delta$ orf 12 in $C$. rodentium) differs from $\Delta \mathrm{L} 32$ by a complete loss of secretion in both translocators and effectors, as reported by Deng et al. (2004) and confirmed in Fig. 4(d). It is therefore conceivable that the intracellular level of EspA in a LEE mutant is independent of bacterial TTS capacity.

To substantiate the notion that L0017 affects EspA expression through a transcriptional event, rather than 
(a)

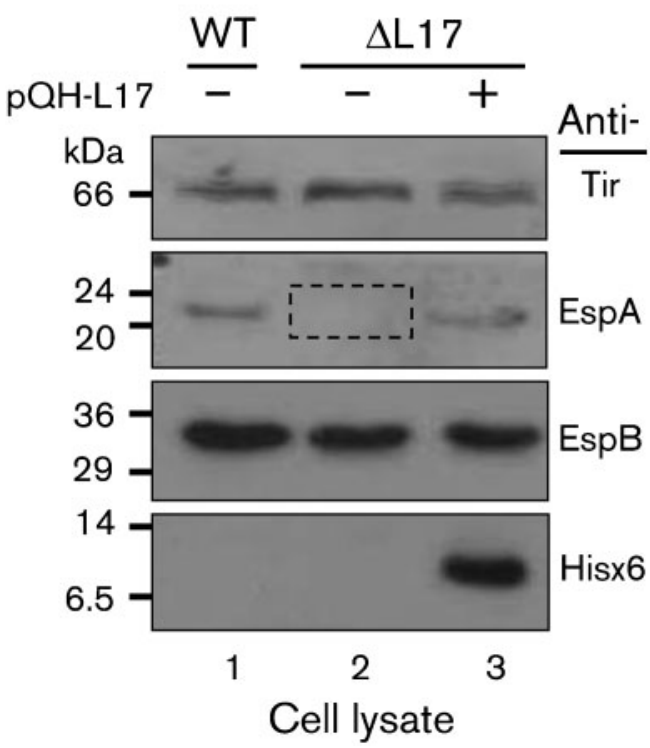

(b)

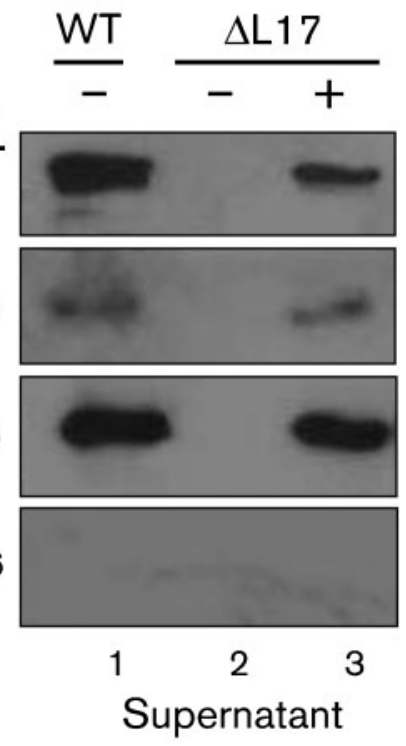

Fig. 3. Western blotting analysis of representative EHEC secreted proteins. (a) Proteins in the cell lysate. Total proteins were prepared from bacteria cultured for $5 \mathrm{~h}$ in $\mathrm{M} 9$ medium at $37{ }^{\circ} \mathrm{C}$ in the presence of $5 \% \mathrm{CO}_{2}$. Proteins were examined by immunoblotting using specific antibodies. pQH-L17 encodes recombinant L0017 N-terminally tagged with His $\times 6$. Note the absence of detectable EspA (dashed box). (b) Proteins secreted into M9 medium. The spent media of EHEC cultures in (a) were concentrated and studied similarly by Western blotting. None of the proteins were detected in the $\Delta \mathrm{L} 17$ culture supernatant unless the deletion mutant was transformed with $\mathrm{pQH}-$ L17. through control of the espA mRNA level, reporter assays were carried out. $l a c Z$ was fused downstream from esp $A$ in two ways, as shown in Fig. 5. First, a transcriptional fusion was made in pKMespAX where lac $Z$ with intact translational initiation elements was inserted immediately downstream of the espA stop codon (Fig. 5a). By doing so, the T5 promoter controls the transcription of an mRNA encoding both espA and lacZ. Since EspA and $\beta$ galactosidase are independently translated but share a common mRNA, any factors from the different host cells that hinder transcription or accelerate the degradation of the mRNA are likely to affect $\beta$-galactosidase activity. (a)

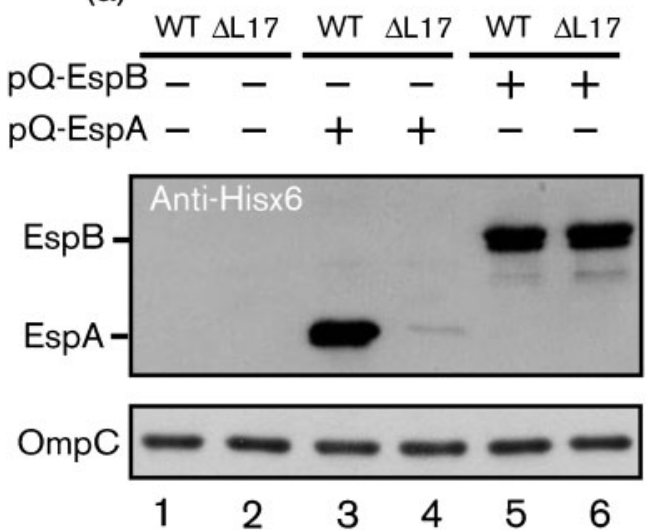

(b)

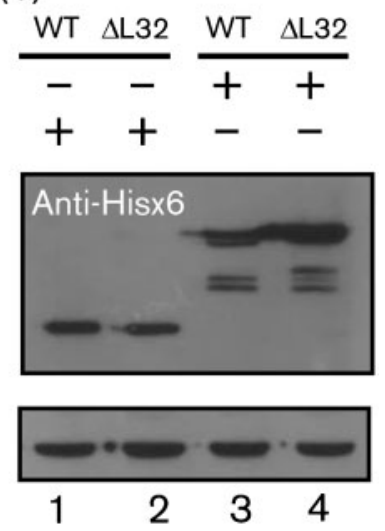

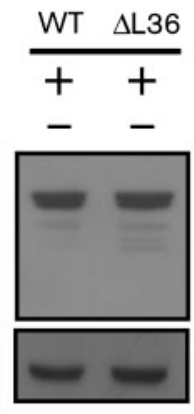

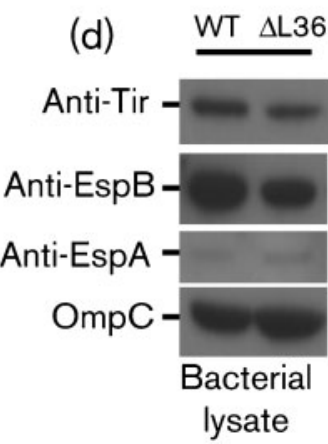

WT $\Delta \mathrm{L} 36$

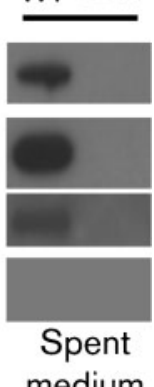

Fig. 4. Effect of gene deletion on EspA expression in EHEC. (a)-(c) Bacteria were transformed with an EspA-expressing plasmid or an EspB-expressing plasmid. The expression levels of the His $\times 6$-tagged proteins in the total bacterial proteins were monitored by Western blotting using anti-His $\times 6$. Detection of OmpC was used to assure comparable protein loadings in each lane. Note, $\Delta \mathrm{L} 32$ is a deletion mutant control with a similar construction to $\Delta \mathrm{L} 17$ except that 10032 within the LEE was deleted; as a consequence, the secretion of translocators is impaired, but not that of effectors (Deng et al., 2004). $\Delta \mathrm{L} 36$ is a similarly constructed but distinct mutant with a deletion at 10036 (Tsai et al., 2006); it abolishes secretion of both translocators and effectors, but does not affect the intracellular levels of these proteins. (d) Western blotting with different antibodies to detect the corresponding proteins in the bacterial lysate and spent medium, to support the characteristics of $\Delta \mathrm{L} 36$ described above. 
(a)

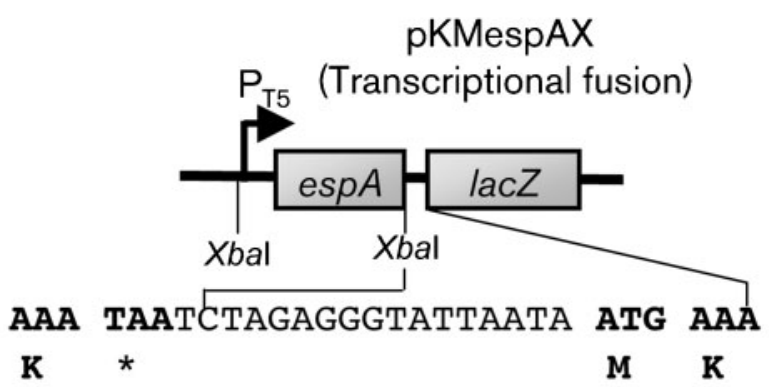

(b)

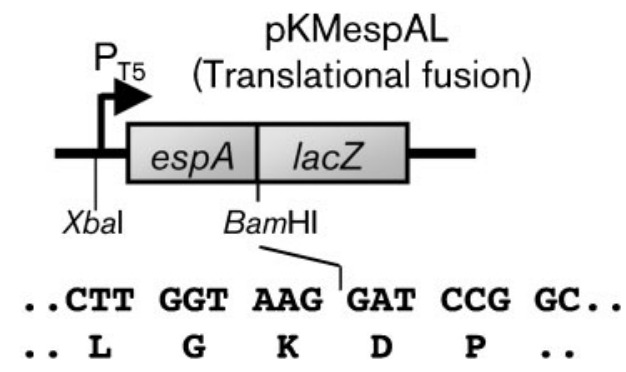

(c)

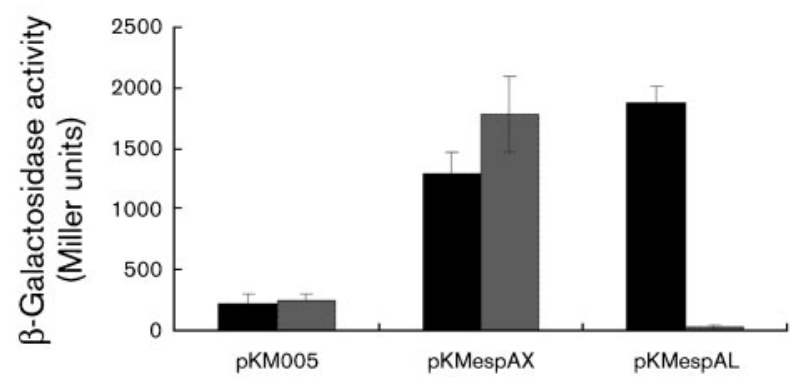

Fig. 5. Reporter assay to study the effect of L0017 on EspA expression. (a) Reporter gene lac $Z$ preceded by esp $A$ in the same operon in a transcriptional fusion. In pKMespAX, a T5 promoterdriven mRNA encodes EspA and $\beta$-galactosidase that both have independent translation initiation and stop codons. Presumably, any effect of a factor on the nucleotide sequence ahead of lac $Z$ would be detected through $\beta$-galactosidase activity. (b) EspA fused to $\beta$-galactosidase in a single ORF. In pKMespAL, the coding sequence of lac $Z$ was directly fused to the $3^{\prime}$ end of espA (without a stop codon) so that a fusion protein EspA- $\beta$ galactosidase is produced. Any external effects on translation or the stability of the fusion protein would be observed by changes in reporter activity. (c) Comparison of reporter activities when assayed in congenic bacteria. Black bars, WT; grey bars, $\Delta \mathrm{L} 17$ pKM005, control vector used for creating pKMespAX and pKMespAL.

Second, a fusion of lac $Z$ in-frame with the $3^{\prime}$ end of espA before the stop codon was constructed in pKMespAL; in this case $\beta$-galactosidase translation directly follows that of EspA (Fig. $5 \mathrm{~b}$ ) because $\beta$-galactosidase with an $\mathrm{N}$-terminal EspA fusion is produced when espA-lac $Z$ is transcribed, and this is subsequently translated. Any effect of the host cells (with or without L0017) on the translation process or on the degradation of the fusion protein will be reflected in the level of $\beta$-galactosidase activity.

After the two constructs were separately transformed into bacteria, the $\beta$-galactosidase activity of the bacteria was measured (Fig. 5c). The enzyme activity was seen to show a 6.8- and 8.1-fold increase in the WT and $\Delta \mathrm{L} 17$ strains, respectively, when the transformants containing pKMespAX were compared to those carrying the control plasmid (pKM005). On the other hand, when the $\beta$ galactosidase activities were compared with those from the pKMespAL transformants, an intriguing difference was observed. There was a 9.6-fold increase in enzyme activity from the pKMespAL-transformed WT strain compared to that from the pK005-transformed WT, whereas there was an opposite effect (a 22-fold reduction) in the case of pKMespAL-transformed $\Delta \mathrm{L} 17$ compared to $\Delta \mathrm{L} 17$ carrying pKM005. The 1.2-fold difference found between the transcriptional fusion data obtained with the WT and $\Delta \mathrm{L} 17$ strains is likely to be due to experimental variation. In contrast, the 210-fold difference seen between the two translational fusion (pKMespAL) results strongly suggests that L0017 regulates at the protein level after the transcription.

There are a number of possible reasons for the posttranscriptional effects of the L0017 protein. These include the stability of the translated protein, which is the easiest scenario to test. To do this, pQ-EspA was transformed separately into the WT and $\Delta \mathrm{L} 17$ strains. After inducing LEE expression for $5 \mathrm{~h}$, ribosomal translation was blocked with chloramphenicol (at a final concentration of $200 \mu \mathrm{g}$ $\mathrm{ml}^{-1}$ ). The existing intracellular EspA was then detected over a period of time by Western blotting. Fig. 6(a) shows that the level of EspA in $\Delta \mathrm{L} 17$ declined quickly within the first hour. By the second hour, EspA is barely detectable. On the other hand, in the WT strain, EspA was relatively stable during the first $2 \mathrm{~h}$, and substantial amounts of EspA remained detectable after inoculation for $16 \mathrm{~h}$ (Fig. 6b). To exclude the possibility that the decreased stability of EspA in $\Delta \mathrm{L} 17$ is simply due to degradation of EspA arising from the loss of bacterial secretion capability, we performed a similar experiment in the control $\Delta$ L36 mutant. Fig. 6(c) shows that EspA was comparably detected in $\Delta \mathrm{L} 36$ over the same period of time as seen in the WT strain (Fig. 6d). Therefore, it would seem that the presence of L0017 stabilizes intracellular EspA in EHEC.

\section{Interaction of EspA and L0017}

To determine whether the stabilization of EspA by L0017 is brought about through direct interaction, pEspA-HisL0017 was used to express RGS-His $\times 6$-tagged L0017 together with a tag-free EspA. Affinity chromatography using a nickel ion column was carried out to purify RGSHis $\times 6$-L0017 and the protein from the column was used to test whether EspA co-purified with the His-tagged protein. Fig. 7(a) shows that EspA was abundantly detected in the eluted fractions when the bacterial proteins loaded 


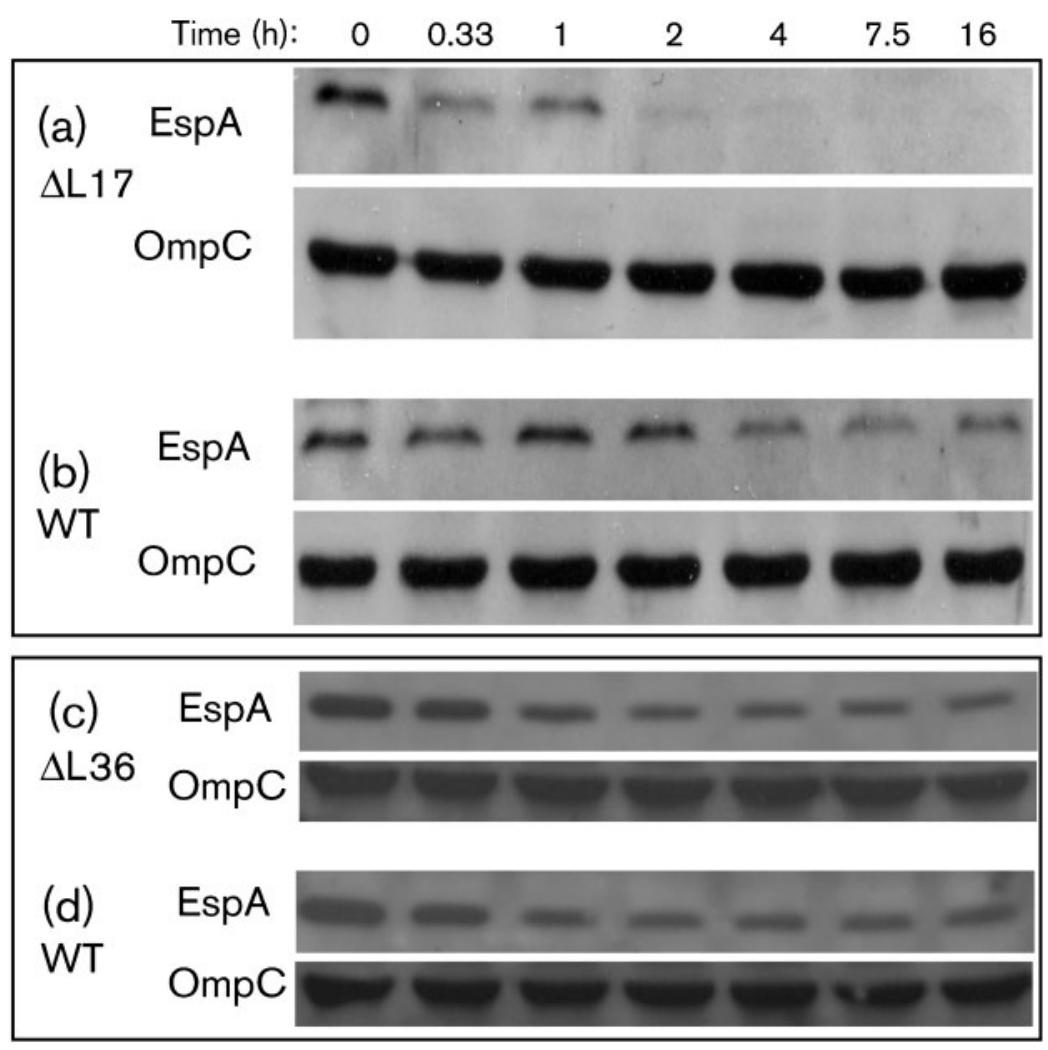

Fig. 6. Stability of EspA in bacteria. Bacteria were transformed to express EspA from pQEspA. After cultivation in M9 medium for $5 \mathrm{~h}$, bacterial protein synthesis was arrested by chloramphenicol and culturing was continued for a period of time before harvesting. Harvested bacteria were dissolved in SDS sample buffer and processed for Western blotting using anti-His $\times 6$ tag antibody. Detection of OmpC was carried out to assure comparable protein loading. In the different experiment panels, the parental WT strain was similarly treated and run in parallel for comparison.

into the column were prepared from bacteria harbouring pEspA-His-L0017. Remarkably, it was seen that EspA was most prominently detected in fractions $2-4$ with intensities directly proportional to the amount of His $\times 6$-L0017 detected, a fact that unequivocally reveals an interaction between EspA and L0017. In contrast, in a control where EspA alone was expressed from pT5-EspA, EspA was detected only in the pass-through and washing fractions, but not in the eluant. Therefore, these biochemical data support that the interaction between EspA and L0017 does occur when they are expressed in the same bacterium. To corroborate this interaction, a bacterial two-hybrid assay was performed (Fig. 7b, inset). When L0017 was cloned as bait, a positive signal was found after pairing with the target of EspA. The interaction seemed to be as strong as L0017 paired with L0053, a previously reported binding protein in the yeast two-hybrid system (Creasey et al., 2003b).

\section{DISCUSSION}

L0017 is a small protein of 92 aa with a predicted pI of 5.5. We have shown that EHEC with an 10017 deletion has a phenotype similar to that of $C$. rodentium with an orf 29 deletion (Deng et al., 2004). Secretion of translocaters (exemplified by EspB) and effectors (exemplified by Tir) were disrupted and the bacterial activities of cell adherence and actin accumulation disappeared. In addition, we located L0017 in the inner-membrane fraction of EHEC, a biochemical property that is consistent with the proposed role of the protein as a TTS component (Deng et al., 2004).

In examining whether L0017 has any additional functions, we have found for the first time that a lack of an innermembrane component from EHEC resulted in a decrease in the intra-bacterial level of EspA, but not of EspB or Tir. Mechanistically, we have ruled out the possibility that L0017 regulates the EspA level at the corresponding promoter. The first line of evidence was obtained by placing espA under the control of an exogenous promoter, such as the T5 promoter, and we found that $\Delta \mathrm{L} 17$ produced a low level of intracellular EspA when compared with its congenic counterpart (Fig. 4). Second, by using a reporter gene transcriptionally fused downstream to esp $A$, the reporter activity of the two strains demonstrated no apparent difference (Fig. 5c). Therefore, it would seem that L0017 regulates EspA expression at a level other than transcription.

When a translational fusion assay was carried out to monitor the EspA- $\beta$-galactosidase fusion protein (Fig. $5 \mathrm{~b}$ ), a 210 -fold difference was found between $\Delta \mathrm{L} 17$ and its parental strain (Fig. 5c). This difference was consistent with the direct detection of the EspA protein seen in Fig. 4. Therefore, these results indicate that for EHEC to keep a constant and high level of EspA in the cytoplasm, the presence of $\mathrm{L} 0017$ is required, perhaps to retain an effective TTS system. The amount of L0017 needed is far less than that of EspA, as revealed by the fact that the level of 
(a) pEspA-His-L0017

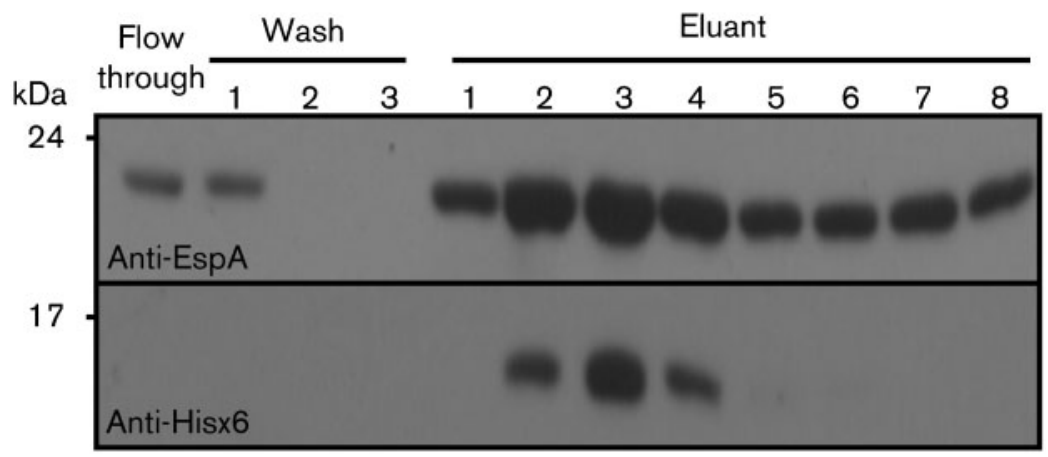

(b) $\mathrm{pT5}-\mathrm{EspA}$

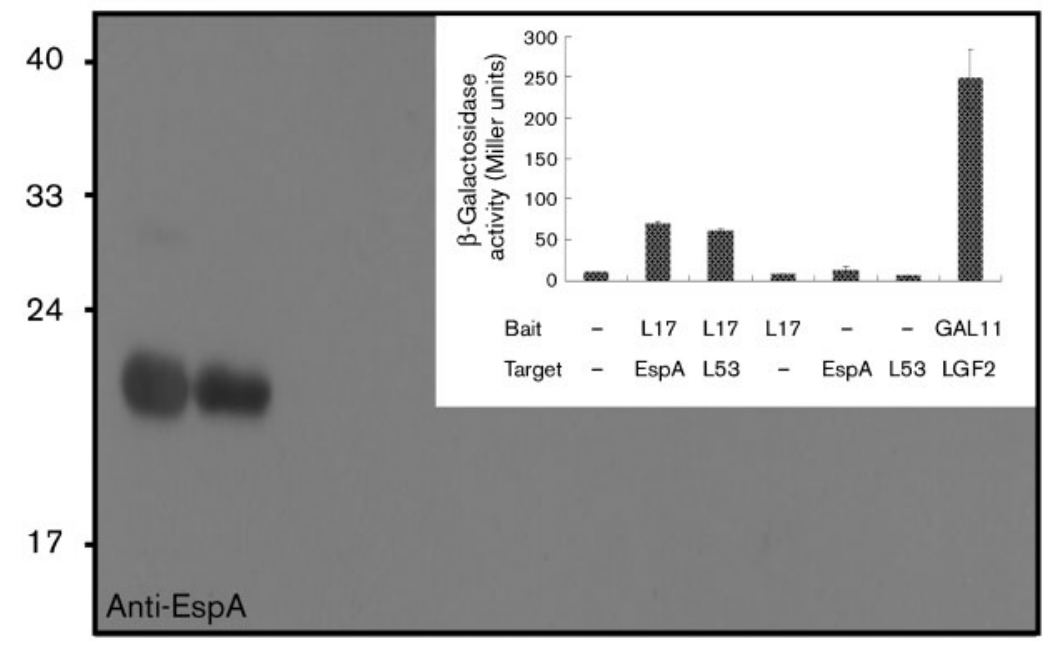

Fig. 7. Interaction of EspA and L0017. (a) Analysis of co-eluted EspA and L0017 in fractions obtained by affinity chromatography using a nickel-NTA column. Bacterial lysate from pT5-EspA-His-L0017-transformed $E$. coli JM109 was loaded onto the column and the flow-through fraction was collected. After washing with $50 \mathrm{mM}$ imidazole, the retained proteins were eluted with $250 \mathrm{mM}$ imidazole. Proteins from these fractions were detected for EspA and L0017 by Western blotting using anti-EspA and anti-His $\times 6$, respectively. (b) Analysis of EspA in chromatography fractions as in (a) except that the bacterial lysate was prepared from JM109 harbouring PT5-EspA. EspA interacting with L0017 was alternatively assayed with a bacterial two-hybrid system (inset). Positive interactions of the cloned target and bait proteins were reported by an increase in $\beta$-galactosidase activity. A reported interaction between L0017 and L0053 (Creasey et al., 2003b) and that between the dimerization domain of yeast transcriptional activator Gal4 (LGF2) and a domain derived from a mutant form of GAL11 (Stratagene) served as positive controls. Vectors only or vector with no gene cloned as a bait or target served as negative controls. intrinsic L0017 was very hard to detect in the WT strain. However, when L0017 is missing, newly synthesized EspA is degraded quickly and the intracellular level of EspA drops aberrantly.

EspA constitutes the major part of the filamentous surface appendages of pathogenic E. coli (Ebel et al., 1998) and it alone is sufficient to form filamentous structures in the absence of other LEE proteins in vitro (Delahay et al., 1999; Yip et al., 2005). How this protein, which has a strong tendency to polymerize, reaches the extracellular surface, remains a puzzle. In a previous model proposed by Yip et al. (2005), the newly synthesized EspA is maintained partially unfolded, with two extensive coiled coils preserved after binding to its intracellular chaperone, CesAB. Since it is known that the CesAB chaperone is not secreted and thus can only act to maintain the monomeric status of EspA monomeric inside the bacterium (Yip et al., 2005), a component of the TTS system must have an adaptor that allows consecutive transit of EspA. From our data above, it can be seen that once the TTS is handicapped by a lack of L0017, intracellular EspA destabilizes. A bridging protein on the membrane apparently is needed to prevent EspA degradation. A study with a yeast two-hybrid system did not detect EspA interacting with a membrane component of the TTS system, except for the known CesAB chaperone (Creasey et al., 2003b). However, such an interaction within the bacterium cannot be completely ruled out by a genetic system that functions in yeast. A prominent undetected example is the interaction of CesD2 and EspD (Creasey et al., 2003b; Neves et al., 2003). Innermembrane association and the ability to stabilize EspA have made L0017 a compelling candidate for handing over the unfolded EspA. This is supported by the co-expression experiment, and we have demonstrated that EspA and L0017 indeed do interact with each other.

Two chaperones (CesD in the cytosol and CesD2 in the inner-membrane fraction) have been found with EspD, which has a high tendency to aggregate (Daniell et al., 2001). However, so far, CesAB is the only known chaperone reported to both stabilize and directly interact with EspA. The characteristic whereby L0017 interacts with EspA, stabilizes EspA expression and is localized on the inner membrane are analogous to those seen with CesD2 and EspD (Neves et al., 2003). Therefore, L0017 should probably be categorized as one of the TTS chaperones and named CesA2, as the second EspA chaperone. This uniqueness makes CesA2 distinct from the inner-membrane-associated SepD-SepL that may 
form a molecular switch to ensure the secretion of translocators prior to effectors, but not to affect their stability (Deng et al., 2005; O'Connell et al., 2004). A speculation is that EspA chaperoned by CesAB and CesA2 may transit outwards via some kind of contact with the SepD-SepL complex. If so, it remains to be explored whether and how EspA interacts with these proteins, including those indirect binders such as L0053, to result in transient complexes.

\section{ACKNOWLEDGEMENTS}

We thank Joaquim Chan-Wang Lio and Dr S. T. Hu for their valuable plasmids. This work was supported in part by a grant from the Ministry of Education, Aim for the Top University Plan and Grant NSC96-2320-B-010-002 from the National Science Council, Republic of China (Taiwan).

\section{REFERENCES}

Chiu, H. J. \& Syu, W. J. (2005). Functional analysis of EspB from enterohaemorrhagic Escherichia coli. Microbiology 151, 3277-3286.

Chiu, H. J., Lin, W. S. \& Syu, W. J. (2003). Type III secretion of EspB in enterohemorrhagic Escherichia coli O157:H7. Arch Microbiol 180, 218-226.

Crane, J. K., McNamara, B. P. \& Donnenberg, M. S. (2001). Role of EspF in host cell death induced by enteropathogenic Escherichia coli. Cell Microbiol 3, 197-211.

Creasey, E. A., Delahay, R. M., Bishop, A. A., Shaw, R. K., Kenny, B., Knutton, S. \& Frankel, G. (2003a). CesT is a bivalent enteropathogenic Escherichia coli chaperone required for translocation of both Tir and Map. Mol Microbiol 47, 209-221.

Creasey, E. A., Delahay, R. M., Daniell, S. J. \& Frankel, G. (2003b). Yeast two-hybrid system survey of interactions between LEEencoded proteins of enteropathogenic Escherichia coli. Microbiology 149, 2093-2106.

Creasey, E. A., Friedberg, D., Shaw, R. K., Umanski, T., Knutton, S., Rosenshine, I. \& Frankel, G. (2003c). CesAB is an enteropathogenic Escherichia coli chaperone for the type-III translocator proteins EspA and EspB. Microbiology 149, 3639-3647.

Daniell, S. J., Delahay, R. M., Shaw, R. K., Hartland, E. L., Pallen, M. J., Booy, F., Ebel, F., Knutton, S. \& Frankel, G. (2001). The coiled coil domain of enteropathogenic Escherichia coli type III secreted protein EspD is involved in EspA filament-mediated cell attachment and hemolysis. Infect Immun 69, 4055-4064.

Day, J. B., Guller, I. \& Plano, G. V. (2000). Yersinia pestis YscG protein is a Syc-like chaperone that directly binds YscE. Infect Immun 68, 6466-6471.

Delahay, R. M., Knutton, S., Shaw, R. K., Hartland, E. L., Pallen, M. J. \& Frankel, G. (1999). The coiled-coil domain of EspA is essential for the assembly of the type III secretion translocon on the surface of enteropathogenic Escherichia coli. J Biol Chem 274, 35969-35974.

Deng, W., Li, Y., Vallance, B. A. \& Finlay, B. B. (2001). Locus of enterocyte effacement from Citrobacter rodentium: sequence analysis and evidence for horizontal transfer among attaching and effacing pathogens. Infect Immun 69, 6323-6335.

Deng, W., Puente, J. L., Gruenheid, S., Li, Y., Vallance, B. A., Vázquez, A., Barba, J., Ibarra, J. A., O'Donnell, P. \& other authors (2004). Dissecting virulence: systematic and functional analyses of a pathogenicity island. Proc Natl Acad Sci U S A 101, 3597-3602.
Deng, W., Li, Y., Hardwidge, P. R., Frey, E. A., Pfuetzner, R. A., Lee, S., Gruenheid, S., Strynakda, N. C., Puente, J. L. \& Finlay, B. B. (2005). Regulation of type III secretion hierarchy of translocators and effectors in attaching and effacing bacterial pathogens. Infect Immun 73, 2135-2146.

Donnenberg, M. S., Yu, J. \& Kaper, J. B. (1993). A second chromosomal gene necessary for intimate attachment of enteropathogenic Escherichia coli to epithelial cells. J Bacteriol 175, 4670-4680.

Ebel, F., Podzadel, T., Rohde, M., Kresse, A. U., Kramer, S., Deibel, C., Guzman, C. A. \& Chakraborty, T. (1998). Initial binding of Shiga toxinproducing Escherichia coli to host cells and subsequent induction of actin rearrangements depend on filamentous EspA-containing surface appendages. Mol Microbiol 30, 147-161.

Elliott, S. J., Krejany, E. O., Mellies, J. L., Robins-Browne, R. M., Sasakawa, C. \& Kaper, J. B. (2001). EspG, a novel type III systemsecreted protein from enteropathogenic Escherichia coli with similarities to VirA of Shigella flexneri. Infect Immun 69, 4027-4033.

Elliott, S. J., O'Connell, C. B., Koutsouris, A., Brinkley, C., Donnenberg, M. S., Hecht, G. \& Kaper, J. B. (2002). A gene from the locus of enterocyte effacement that is required for enteropathogenic Escherichia coli to increase tight-junction permeability encodes a chaperone for EspF. Infect Immun 70, 2271-2277.

Frankel, G., Phillips, A. D., Rosenshine, I., Dougan, G., Kaper, J. B. \& Knutton, S. (1998). Enteropathogenic and enterohaemorrhagic Escherichia coli: more subversive elements. Mol Microbiol 30, 911-921.

Hsu, S. C., Yan, B. S., Pan, J. M. \& Syu, W. J. (1997). A monoclonal antibody reacts with maltose-binding protein of Escherichia coli and related enteric bacteria. J Immunol Methods 204, 169-174.

Jerse, A. E. \& Kaper, J. B. (1991). The eae gene of enteropathogenic Escherichia coli encodes a 94-kilodalton membrane protein, the expression of which is influenced by the EAF plasmid. Infect Immun 59, 4302-4309.

Kenny, B., Lai, L. C., Finlay, B. B. \& Donnenberg, M. S. (1996). EspA, a protein secreted by enteropathogenic Escherichia coli, is required to induce signals in epithelial cells. Mol Microbiol 20, 313-323.

Kenny, B., Abe, A., Stein, M. \& Finlay, B. B. (1997a). Enteropathogenic Escherichia coli protein secretion is induced in response to conditions similar to those in the gastrointestinal tract. Infect Immun 65, 2606-2612.

Kenny, B., DeVinney, R., Stein, M., Reinscheid, D. J., Frey, E. A. \& Finlay, B. B. (1997b). Enteropathogenic E. coli (EPEC) transfers its receptor for intimate adherence into mammalian cells. Cell 91, 511-520.

Kresse, A. U., Rohde, M. \& Guzman, C. A. (1999). The EspD protein of enterohemorrhagic Escherichia coli is required for the formation of bacterial surface appendages and is incorporated in the cytoplasmic membranes of target cells. Infect Immun 67, 4834-4842.

Lai, L. C., Wainwright, L. A., Stone, K. D. \& Donnenberg, M. S. (1997). A third secreted protein that is encoded by the enteropathogenic Escherichia coli pathogenicity island is required for transduction of signals and for attaching and effacing activities in host cells. Infect Immun 65, 2211-2217.

Lee, A. T. \& Cerami, A. (1987). Elevated glucose 6-phosphate levels are associated with plasmid mutations in vivo. Proc Natl Acad Sci U S A 84, 8311-8314.

Link, A. J., Phillips, D. \& Church, G. M. (1997). Methods for generating precise deletions and insertions in the genome of wild-type Escherichia coli: application to open reading frame characterization. J Bacteriol 179, 6228-6237.

Masui, Y., Coleman, J. \& Inouye, M. (1983). Experimental Manipulation of Gene Expression, pp. 15-32. Edited by M. Inouye. New York: Academic Press. 
McDaniel, T. K., Jarvis, K. G., Donnenberg, M. S. \& Kaper, J. B. (1995). A genetic locus of enterocyte effacement conserved among diverse enterobacterial pathogens. Proc Natl Acad Sci U S A 92, 1664-1668.

Mellies, J. L., Elliott, S. J., Sperandio, V., Donnenberg, M. S. \& Kaper, J. B. (1999). The Per regulon of enteropathogenic Escherichia coli: identification of a regulatory cascade and a novel transcriptional activator, the locus of enterocyte effacement (LEE)-encoded regulator (Ler). Mol Microbiol 33, 296-306.

Miller, J. H. (1972). Experiments in Molecular Genetics. Cold Spring Harbor, NY: Cold Spring Harbor Laboratory.

Mundy, R., Petrovska, L., Smollett, K., Simpson, N., Wilson, R. K., Yu, J., Tu, X., Rosenshine, I., Clare, S. \& other authors (2004). Identification of a novel Citrobacter rodentium type III secreted protein, EspI and roles of this and other secreted proteins in infection. Infect Immun 72, 2288-2302.

Nataro, J. P. \& Kaper, J. B. (1998). Diarrheagenic Escherichia coli. Clin Microbiol Rev 11, 142-201.

Neves, B. C., Mundy, R., Petrovska, L., Dougan, G., Knutton, S. \& Frankel, G. (2003). CesD2 of enteropathogenic Escherichia coli is a second chaperone for the type III secretion translocator protein EspD. Infect Immun 71, 2130-2141.

O'Connell, C. B., Creasey, E. A., Knutton, S., Elliott, S., Crowther, L. J., Luo, W., Albert, M. J., Kaper, J. B., Frankel, G. \& Donnenberg, M. S. (2004). SepL, a protein required for enteropathogenic Escherichia coli type III translocation, interacts with secretion component SepD. Mol Microbiol 52, 1613-1625.

Pallen, M. J., Beatson, S. A. \& Bailey, C. M. (2005). Bioinformatics analysis of the locus for enterocyte effacement provides novel insights into type-III secretion. BMC Microbiol 5, 9.

Quinaud, M., Chabert, J., Faudry, E., Neumann, E., Lemaire, D., Pastor, A., Elsen, S., Dessen, A. \& Attree, I. (2005). The PscE-PscFPscG complex controls type III secretion needle biogenesis in Pseudomonas aeruginosa. J Biol Chem 280, 36293-36300.

Roe, A. J., Hoey, D. E. \& Gally, D. L. (2003). Regulation, secretion and activity of type III-secreted proteins of enterohaemorrhagic Escherichia coli O157. Biochem Soc Trans 31, 98-103.

Tsai, N. P., Wu, Y. C., Chen, J. W., Wu, C. F., Tzeng, C. M. \& Syu, W. J. (2006). Multiple functions of 10036 in the regulation of the pathogenicity island of enterohaemorrhagic Escherichia coli O157:H7. Biochem J 393, 591-599.

Wainwright, L. A. \& Kaper, J. B. (1998). EspB and EspD require a specific chaperone for proper secretion from enteropathogenic Escherichia coli. Mol Microbiol 27, 1247-1260.

Yip, C. K., Finlay, B. B. \& Strynadka, N. C. (2005). Structural characterization of a type III secretion system filament protein in complex with its chaperone. Nat Struct Mol Biol 12, 75-81.

Edited by: B. Kenny 